\title{
Alicellidae and Valettiopsidae, two new callynophorate families (Crustacea: Amphipoda)
}

\author{
J.K. LOWRY ${ }^{1} \&$ C. DE BROYER ${ }^{2}$ \\ ${ }^{\text {I} C r u s t a c e a ~ S e c t i o n, ~ A u s t r a l i a n ~ M u s e u m, ~} 6$ College Street, Sydney, NSW 2010, Australia.E-mail: jim.lowry@austmus.gov.au \\ ${ }^{2}$ Royal Belgian Institue of Natural Sciences, Departement of Invertebrates (Carcinology), 29 Rue Vautier, B-1000 Bruxelles, Belgium. \\ E-mail: claude.debroyer@naturalsciences.be
}

\begin{abstract}
Two new families, the Alicellidae fam. nov. and the Valettiopsidae fam. nov., are described based on genera traditionally considered as lysianassoid amphipods. The Alicellidae fam. nov. are deep-sea scavengers often associated with thermal vents. They are distinguished from all other amphipods by a combination of characters which includes a callynophore on antenna 1; a broad, serrate left lacinia mobilis (occasionally narrow or vestigial) and a reduced or vestigial right lacinia mobilis (occasionally broad and serrate); simple or subchelate gnathopod 1; an elongate ischium, rectolinear carpus and propodus and a small dactylus on gnathopod 2 (not mitten-shaped); absence of apical robust setae on uropods 1 and 2 and a deeply cleft telson. The family contains 6 genera: Alicella Chevreux, 1899; Apotectonia Barnard \& Ingram, 1990; Diatectonia Barnard \& Ingram, 1990; Paralicella Chevreux, 1908; Tectovalopsis Barnard \& Ingram, 1990; Transtectonia Barnard \& Ingram, 1990. The Valettiopsidae fam. nov. are deep-sea scavenging amphipods defined by a combination of characters which includes a callynophore on antenna 1; serrate, curved incisors; a well developed, serrate lacinia mobilis on each mandible, an oblique setal row on the inner plate of maxilla 2, an elongate ischium on gnathopod 2; the absence of robust setae on the apices of uropods 1 and 2 and a deeply cleft telson. The family contains two genera, Valettiopsis Holmes, 1908 and Valettietta Lincoln \& Thurston, 1983.
\end{abstract}

Key words: Crustacea, Amphipoda, new families, taxonomy, Alicellidae, Valettiopsidae

\section{Introduction}

Dana (1849) described the distinctive family Lysianassidae. These highly recognizable amphipods have a hard enamel-like cuticle; short, robust peduncle of the first antennae; smooth blade-like incisors; a reduced left lacinia mobilis and vestigial or absent right lacinia mobilis; and gnathopod 2 with an elongate ischium, a carpus/propodus with patches of complex setae ('pineapple cushion' in the sense of J.L. Barnard, 1969) and a minute dactylus ('mitten-shaped' in the sense of Barnard \& Karaman 1991). These characters form such a distinctive 'jizz' that all genera up to Bousfield (1987), who re-established the Trischizostomatidae Lilljeborg, 1865, were referred to the Lysianassidae. Bousfield (1979) set up a superfamily Lysianassoidea which included only that family.

Although a 'lysianassid' was always easy to recognise it is not so easy to define. The characters on which everything hinged have been the distinctive 'mitten-shape' (in the sense of Barnard \& Karaman 1991) of gnathopod 2 and in a more understated way, the lack of a lacinia mobilis on the right mandible. Lysianassid/lysianassoid amphipods occur in many habitats and have a lot of morphological diversity. In the last two decades the Lysianassidae has been divided into 12 families (Bousfield 1987; Lowry \& Stoddart, 1990, 1995, 1996, 1997, 2002; Stoddart \& Lowry 2004) and this process is continuing. The 'mitten-shaped' second gnathopod 
and the lacinia mobilis are coming under more detailed examination and this is changing the original lysianassid/lysianassoid concept. The Amaryllididae Lowry \& Stoddart, 2002 for instance, have a well developed left lacinia mobilis which is modified differently to other lysianassoids and although the dactylus of the second gnathopod is small, it is never minute, and it does not have a typical 'mitten-shape'. In this paper we describe two new families based on taxa which have traditionally been considered as lysianassoids, but which possess characters which indicate otherwise.

\section{Alicella group}

Alicella was described by Chevreux, 1899, based on deep-sea trap collections from the North Atlantic Ocean. Paralicella Chevreux, 1908, was described 9 years later also based on deep-sea trap collections from the North Atlantic. Nearly 100 years later Barnard \& Ingram (1990) described a group of genera (Apotectonia, Diatectonia, Tectovalopsis, Transtectonia) from trap collections near deep-sea vents in the North Pacific Ocean. Except for De Broyer \& Thurston (1987) these genera have always been considered as lysianassoid amphipods in the family Lysianassidae (e.g. Barnard \& Ingram (1986), Barnard \& Ingram (1990)).

Although Alicella and Paralicella have always been considered as sister taxa (J.L. Barnard 1969; Barnard \& Karaman 1991) and the genera of Barnard \& Ingram (1990) have been considered as closely related, the combined group, until now, has never been considered as monophyletic. Based on the combination of the usually broad (occasionally narrow or vestigial), serrate left lacinia mobilis, the usually vestigial (occasionally broad and serrate), but always present, right lacinia mobilis, the non- (or very weakly) triturative molar, the elongate ischium of gnathopod 1 and the elongate ischium and rectolinear carpus and propodus of the second gnathopod with a small (but not minute) dactylus, we think these taxa form a monophyletic group. Whether they should be considered as part of the Lysianassoidea as currently defined is debatable, because they have a right lacinia mobilis and they do not have a mitten-shaped gnathopod 2 (in the sense of Barnard \& Karaman 1991). Where known (see De Broyer \& Thurston (1987)), the calceoli differ in several features from the lysianassoid types described by Lincoln \& Hurley (1981). In this paper we establish the family Alicellidae for this group of genera.

\section{Valettiopsis group}

Valettiopsis Holmes, 1908 was originally described in the family Lysianassidae and has remained in the family, right up to Horton (2004) and Hendrycks (2007). Valettietta Lincoln \& Thurston, 1983, was described as a sister taxon to Valettiopsis. Thurston (1989) questioned the placement of these genera in the Lysianassidae. Valettiopsis ruffoi Serejo \& Wakabara, 2003, was described in the genus Valettiopsis, but it has the mouthparts of an alicellid and in our opinion it should be removed to the alicellid genus Tectovalopsis.

Members of the Valettiopsis group cannot be lysianassoid amphipods. The most obvious differences are the mandibles in which the incisors have curved, serrated margins similar to those of the eusirids (sensu stricto), and a well developed serrate lacinia mobilis on both the left and right mandibles, unlike any lysianassoid. The second gnathopod has an elongate ischium, similar to lysianassoids, but it is not 'mitten-shaped'. Valettiopsids are not eusirids for several reasons: the most obvious are the calceoli which are unique to the group (Lincoln \& Thurston 1983); the inner plate of maxilla 1 which has setae along the entire medial margin; and the elongate ischium on gnathopod 2. They are not valettids mainly because of the structure of the maxilliped (Thurston 1989). We establish a new family, Valettiopsidae, for this group.

\section{Materials and methods}

The taxonomic descriptions presented in this paper were generated from a DELTA (Dallwitz 2005) database to world amphipod families. The character set used to produce the family level descriptions was generated by 
diagnosing each callynophorate family (88 families) against every other callynophorate family using Intkey (Dallwitz 2005). The resulting group of characters forms the family level character set. Bolded characters in the taxonomic text are diagnostic. The following abbreviations are used on the plates: $\mathbf{C}$, coxa; $\mathbf{G}$, gnathopod; Hd, head; L, labium; Md, mandible; Mp, maxilliped; Mx, maxilla; T, telson; U, uropod; Ur, urosomite; l, left; $\mathbf{r}$, right.

\section{Taxonomy}

\section{Alicellidae new family}

Type genus. Alicella Chevreux, 1899.

Description. Head exposed; deeper than long; anteroventral margin concave or rounded, weakly or moderately recessed or not recessed, moderately excavate or not excavate; anteroventral corner rounded, subquadrate or absent; rostrum vestigial or absent; eyes present or absent, if present then small, oval. Body laterally compressed.

Antenna 1 shorter than or subequal in length to antenna 2; peduncle 3-articulate, with sparse slender setae; peduncular article 1 longer than article 2; article 2 longer than article 3; peduncular articles not geniculate; accessory flagellum short; callynophore present; calceoli present (Lincoln \& Hurley 1981). Antenna 2 short or medium length; peduncle with sparse slender setae, without brush setae; without hook-like process; flagellum longer than peduncle, 5 or more articulate.

Mouthparts well developed, forming a subquadrate bundle. Mandible incisors asymmetrical, straight or slightly curved, smooth to minutely dentate anteriorly, posterodistal part of incisor becoming strongly dentate; lacinia mobilis present on both mandibles (left broader than deep with serrate margin, occasionally narrow or vestigial; right reduced or vestigial, occasionally broadened with serrate margin); molar present, non-triturative or with tiny triturating patch; palp present. Maxilla 1 inner plate setose along medial margin; outer plate with $8 / 3$ setal-tooth formula; palp symmetrical, 2-articulate. Maxilla 2 inner plate at least 3/4 length of outer plate; inner plate with oblique setal row. Maxilliped inner plates well developed, separate; outer plate longer than palp article 1, not longer than palp article 2; palp 4-articulate.

Pereon. Pereonites 1-7 separate; complete; pleurae absent. Coxae 1-7 well developed, none fused with pereonites, overlapping, none acute ventrally. Coxae 1-3 well developed, none hidden or vestigial and hidden by other coxae. Coxae $2-4$, none extensively broadened.

Gnathopod 1 similar in males and females; smaller (or weaker) than or similar in size to gnathopod 2; similar in form to gnathopod 2; simple or subchelate; coxa smaller than or subequal to coxa 2, not produced anteroventrally; ischium elongate, about $2 \mathrm{x}$ as long as broad; merus and carpus not rotated; carpus shorter than, subequal to, or longer than propodus; dactylus large. Gnathopod 2 similar in males and females (not sexually dimorphic); subchelate to minutely subchelate; coxa subequal to but not hidden by coxa 3; ischium long; carpus/propodus elongate, rectolinear; carpus long, not produced along posterior margin of propodus; propodus without complex setae along posterodistal margin; dactylus small.

Pereopods, none prehensile, 3-7 without hooded dactyli. Pereopod 3 coxa longer than broad or as long as broad; carpus shorter than or subequal to propodus, not produced; dactylus well developed. Pereopod 4 coxa subequal to or larger than coxa 3, not ventrally acute, with small to large posteroventral lobe; carpus shorter than or subequal to propodus, not produced; dactylus well developed. Pereopods 5-7 with few robust or slender setae. Pereopod 5 shorter than or subequal in length to pereopod 6; coxa smaller than or subequal to coxa 4, coxa equilobate; basis expanded, subquadrate, without posteroventral lobe; carpus linear; dactylus with setae absent. Pereopod 6 subequal in length to or longer than pereopod 7; basis expanded; dactylus without setae. Pereopod 7 longer than pereopod 5, similar in structure to pereopod 6; basis expanded, without dense 
slender setae; dactylus minute (less than 1/8 length of propodus), short (between 1/8 and1/4 length of propodus) or medium length (1/4 to $1 / 2$ length of propodus).

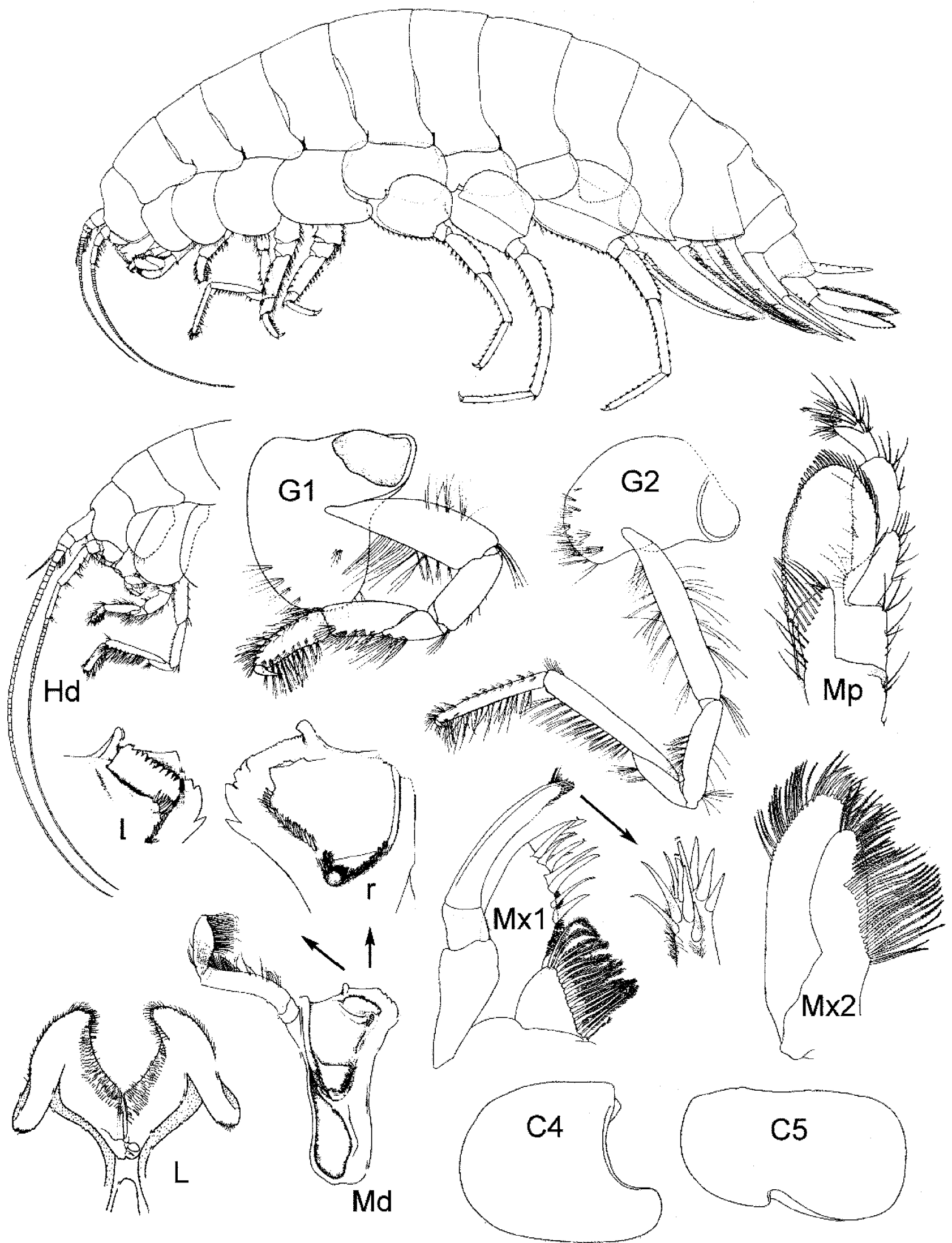

FIGURE 1. Alicellidae fam. nov. (Hd: Tectovalopsis wegeneri ; L. Mp: Apotectonia heterostegos after Barnard \& Ingram 1990; remainder: Alicella gigantea after De Broyer \& Thurston 1987). 


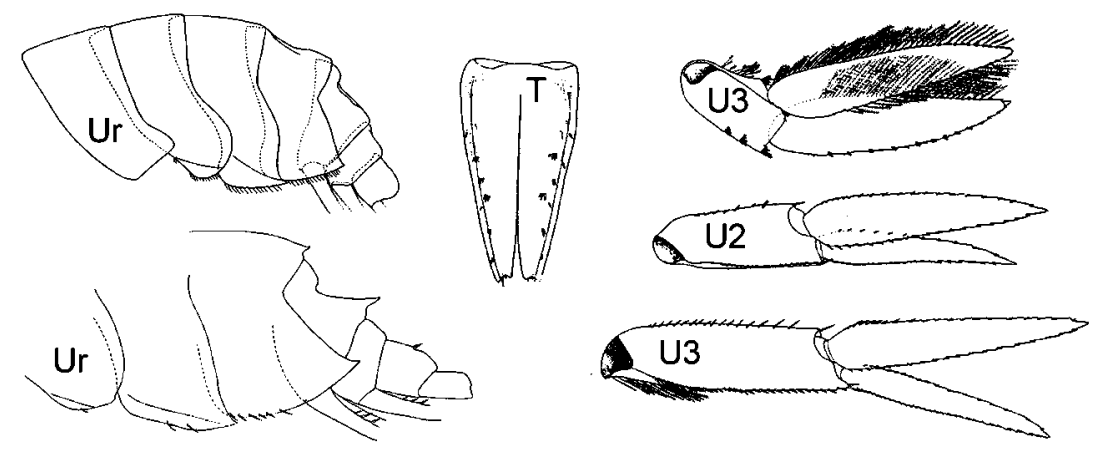

FIGURE 2. Alicellidae fam. nov. (lower left: Ur: Tectovalopsis regelatus after Barnard \& Ingram 1990; remainder: Alicella gigantea after De Broyer \& Thurston 1987).

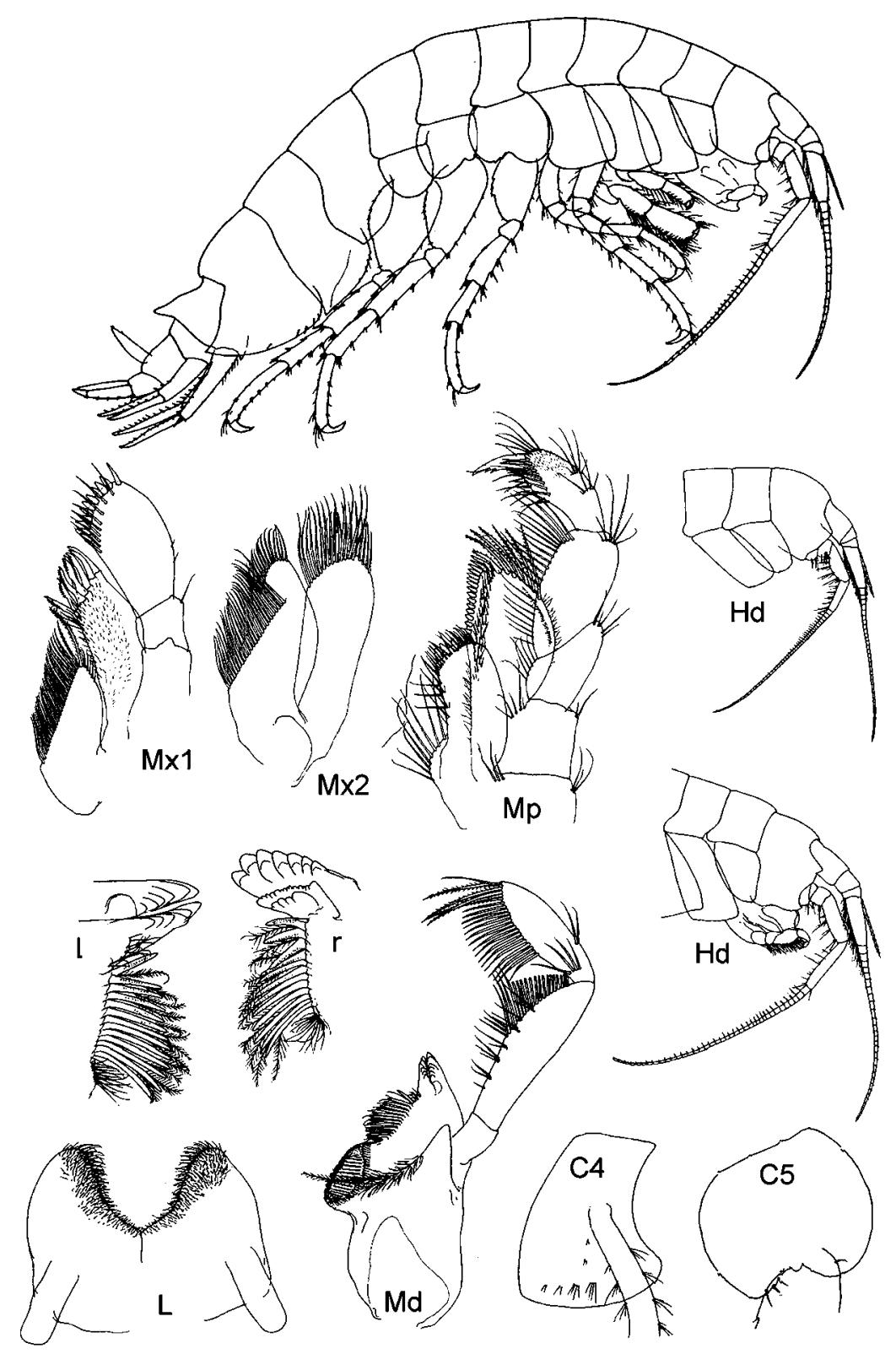

FIGURE 3. Valettiopsidae fam. nov. In toto, Mx1, Mx2, Mp, Hd (lower right), C5: Valettiopsis macrodactyla; Hd (upper right), Md, C4: Valettietta lobata; L: Valettietta gracilis (after Lincoln \& Thurston 1983). 

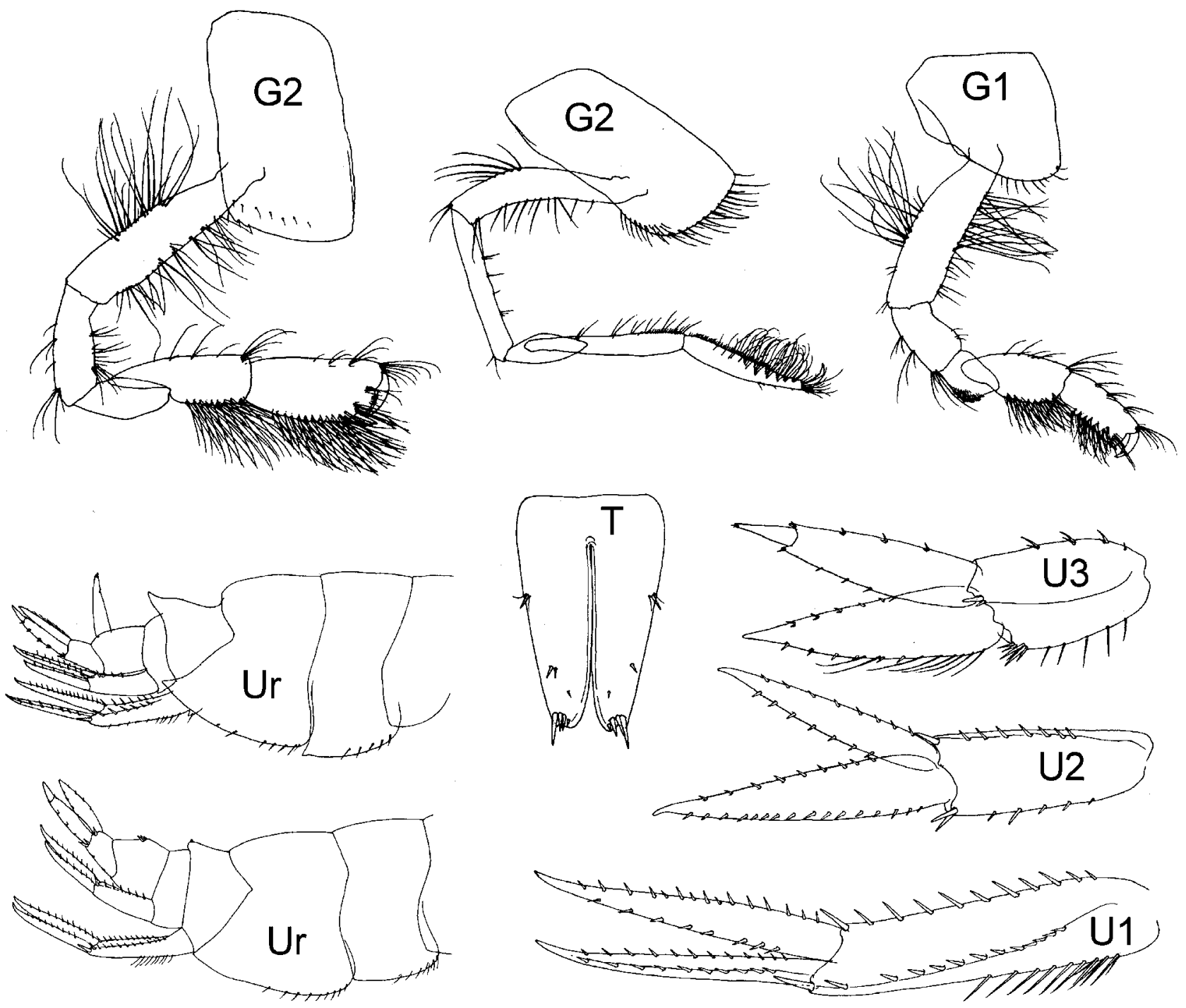

FIGURE 4. Valettiopsidae fam. nov., G1, G2 (left), Ur (upper left), T: Valettiopsis macrodactyla; G2 (upper centre):Valettietta gracilis; Ur (lower left), U1-3: Valettietta lobata (after Lincoln \& Thurston 1983).

Pleon. Pleonites 1-3 without transverse dorsal serrations, pleonite 3 with or without dorsal spines, without lateral teeth or ridging, without dorsal carina. Epimeron 1 well developed. Epimeron 2 setose.

Urosome not dorsoventrally flattened; urosomites 1-3 free; urosomite 1 carinate or not. Urosomite 3 not fused with telson. Uropods 1-2 apices of rami without robust setae or setae embedded. Uropod 1 peduncle without long plumose setae; biramous. Uropod 2 well developed; without dorsal flange; inner ramus subequal in length to or longer than outer ramus. Uropod 3 not sexually dimorphic; without medial process; biramous; outer ramus longer than peduncle; inner ramus subequal to outer ramus. Telson longer than broad; deeply cleft; dorsal or lateral robust setae present; apical slender setae absent; apical robust setae present.

Included genera. The Alicellidae includes 6 genera: Alicella Chevreux, 1899; Apotectonia Barnard \& Ingram, 1990; Diatectonia Barnard \& Ingram, 1990; Paralicella Chevreux, 1908; Tectovalopsis Barnard \& Ingram, 1990; Transtectonia Barnard \& Ingram, 1990.

Remarks. Alicellids are distinguished from other callynophorate amphipod families by the following combination of characters: both mandibles with lacinia mobilis; gnathopod 2 with elongate ischium, elongate, rectolinear carpus and propodus and small to medium dactylus; uropods 1-2 without apical robust setae; telson deeply cleft. De Broyer \& Thurston (1987) reported type 1 calceoli in Alicella. This is unexpected because type 1 calceoli usually occur only in gammaroid amphipods. 
Alicellids are callynophorate amphipods. Although they are similar to lysianassoid amphipods they differ from lysianassoids by the presence of a right lacinia mobilis and the non-mitten-shaped second gnathopod. Alicellids and amaryllidids have similarities. In both families the left lacinia mobilis is broad with a serrate distal margin, the first gnathopod has a reduced coxa, the second gnathopod has an elongate ischium, a rectolinear carpus and propodus with a small dactylus, but amaryllidids have type 3 calceoli, they do not have a right lacinia mobilis, maxilla 1 inner plate is apically setose and the outer plate has a $6 / 5$ seta-tooth formula, and the telson is ventrally swollen proximally and never deeply cleft. Amaryllidids may occasionally turn up in a baited trap, but they are not scavengers. Vijayines are free-living usually deep-sea amphipods and amaryllidines are often associated with bryozoans or soft corals and it is possible they feed on the polyps.

Among the Cebocaris group Cyclocaris Stebbing, 1888, is a deep-sea scavenger, which is similar to the alicellids, particularly gnathopod 2 with its elongate ischium, rectolinear carpus and propodus and small dactylus, but Cyclocaris has a hugely expanded incisor on the right mandible, the left lacinia mobilis is a vestigial peg, longer than broad, the right lacinia mobilis is absent, the inner plate of maxilla 2 has no oblique setal row and is half the length of the outer plate, both coxae 1 and 2 are vestigial and the posteroventral lobe on coxa 4 is well developed.

Further outside the lysianassoid group alicellids show affinities to the Miramarassidae Lowry, 2006. Both have uropods 1 and 2 lack apical robust setae, deeply cleft telsons, elongate ischia on gnathopod 2 with rectolinear carpi and propodi and a lacinia mobilis on both mandibles. But among other differences, the miramarassids have apparent symmetrical dentate incisors and the lacinia mobiles are well developed and symmetrical.

Alicellids might be similar to some scopelocheirids such as Paracallisoma Chevreux, 1903 and Scopelocheiropsis Schellenberg, 1926, which have rectolinear second gnathopods, although not as well developed.

Members of the Alicellidae are all deep-sea scavengers and the highly modified mandibles appear to be an important modification to this mode of life. Alicellids may be associated with thermal vents (Barnard \& Ingram 1990) or living on the deep abyssal and hadal plains where species such as Alicella gigantea are among the deepest living and largest amphipods known (Chevreux 1899; Barnard \& Ingram 1986; De Broyer \& Thurston 1987).

Distribution. Probably cosmopolitan in the deep-sea, 706-8480 m.

\section{Key to genera}

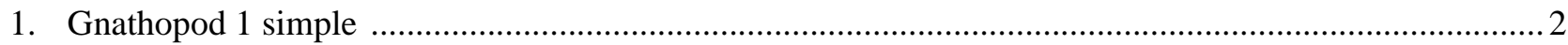

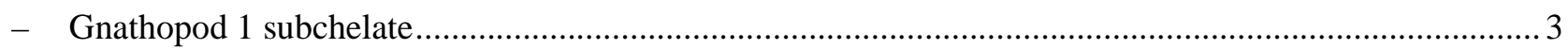

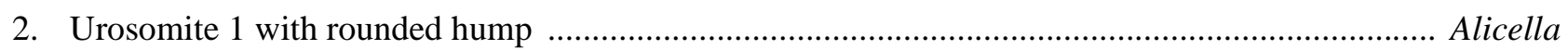

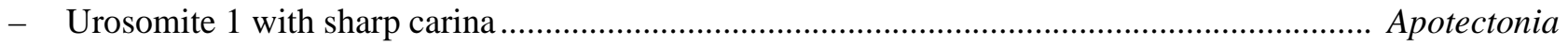

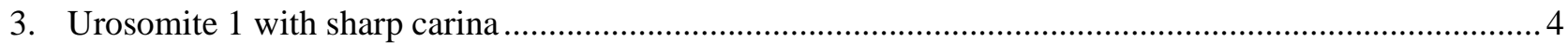

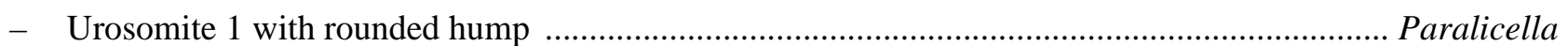

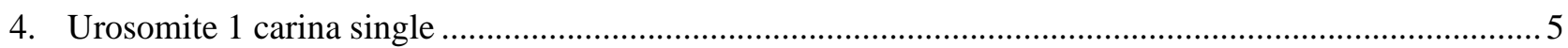

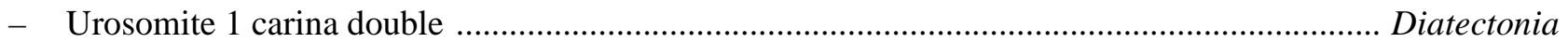

5. Gnathopod 1 coxa reduced, smaller than coxa 2 .............................................................. Tectovalopsis

- Gnathopod 1 coxa large, subequal to coxa 2 .................................................................... Transtectonia 


\section{Valettiopsidae new family}

Type genus. Valettiopsis Holmes, 1908.

Description. Head exposed; as long as deep or deeper than long; anteroventral margin concave, weakly recessed, moderately excavate; anteroventral corner subquadrate; rostrum vestigial or absent; eyes absent. Body laterally compressed.

Antenna 1 shorter than or subequal in length to antenna 2; peduncle 3-articulate, with sparse slender setae; peduncular article 1 longer than article 2; article 2 longer than article 3; peduncular articles not geniculate; accessory flagellum short; callynophore present; calceoli present or absent. Antenna 2 short or medium length; peduncle with many slender or sparse setae; without hook-like process; flagellum longer than peduncle, 5 or more articulate.

Mouthparts well developed, forming a subquadrate bundle. Mandible incisors symmetrical, dentate, curved; lacinia mobilis present on both mandibles (blade-like, broader than long, with serrate margin); molar strongly triturative; palp present. Maxilla 1 inner plate setose along medial margin; outer plate with 6/5 setal-tooth formula; palps symmetrical, 2-articulate. Maxilla 2 inner and outer plates subequal in length; inner plate with oblique setal row. Maxilliped inner plates well developed, separate; outer plate longer than palp article 1, not longer than palp article 2; palp 4-articulate.

Pereon. Pereonites 1-7 separate, complete; pleurae absent. Coxae 1-7 well developed, none fused with pereonites, overlapping, none ventrally acute. Coxae 1-3 well developed, none hidden or some coxae vestigial and hidden by other coxae. Coxae 2-4, none extensively broadened.

Gnathopod 1 similar in males and females; smaller (or weaker) than or similar in size to gnathopod 2; similar in form to gnathopod 2; subchelate; coxa smaller than or subequal to coxa 2, not produced anteroventrally; ischium elongate, 1.5-2 $\mathrm{x}$ as long as broad; merus and carpus not rotated; carpus shorter than or subequal to propodus; dactylus large. Gnathopod 2 similar in males and females (not sexually dimorphic); subchelate; coxa subequal to but not hidden by coxa 3 ; ischium long; carpus/propodus not rectolinear; carpus long, not produced along posterior margin of propodus, projecting between merus and carpus; propodus without complex setae along posterodistal margin; propodus without complex setae along posterodistal margin; dactylus well developed.

Pereopods, none prehensile, 3-7 without hooded dactyli. Pereopod 3 coxa longer than broad; carpus shorter than or subequal to propodus, not produced; dactylus well developed. Pereopod 4 coxa subequal to or larger than coxa 3, not ventrally acute, with well developed or with small posteroventral lobe; carpus shorter than or subequal to propodus, not produced; dactylus well developed. Pereopods 5-7 with few robust or slender setae. Pereopod 5 shorter than or subequal in length to pereopod 6; coxa smaller than coxa 4, equilobate or with large or small anteroventral lobe; basis expanded, subrectangular, subquadrate or subovate, with or without posteroventral lobe; carpus linear; dactylus with setae absent. Pereopod 6 subequal in length to or longer than pereopod 7; basis expanded or slightly expanded; dactylus without setae. Pereopod 7 longer than pereopod 5, similar in structure to pereopod 6; basis expanded or slightly expanded, without dense slender setae; dactylus short (between 1/8 and1/4 length of propodus) or medium length (1/4 to 1/2 length of propodus).

Pleon. Pleonites 1-3 without transverse dorsal serrations, 1-2 each with or without dorsal spine, without lateral teeth or ridging, without dorsal carina. Epimeron 1 well developed. Epimeron 2 setose along ventral margin.

Urosome not dorsoventrally flattened; urosomites 1-3 free; urosomite 1 carinate or not. Urosomite 3 not fused with telson. Uropods 1-2 apices of rami without robust setae or setae embedded. Uropod 1 peduncle without long plumose setae; biramous. Uropod 2 well developed; without dorsal flange; inner ramus subequal in length to or longer than outer ramus. Uropod 3 not sexually dimorphic; without medial process; biramous; outer ramus longer than peduncle; inner ramus subequal to outer ramus. Telson longer than broad; deeply cleft; dorsal or lateral robust setae present or absent; apical slender setae absent; apical robust setae present. 
Included genera. The Valettiopsidae includes 2 genera: Valettietta Lincoln \& Thurston, 1983; Valettiopsis Holmes, 1908.

Remarks. Valettiopsids are deep-sea scavengers, occurring from the continental shelf down to $4300 \mathrm{~m}$ depth. Valettiopsids have been compared to valettid amphipods (Thurston 1989) which are close associates of deep-sea holothurians. Both families are callynophorate amphipods, both have curved dentate incisors, triturating molars, marginal setae along the inner plate of maxilla 1 , elongate ischium on gnathopod 2, equilobate coxa on pereopod 5, no robust apical setae on uropods 1 and 2 and deeply cleft telsons. However valettids do not have an oblique setal row on the inner plate of maxilla 2, the outer maxillipedal plate does not have apical robust or slender setae and the telson is shorter and bears no setae.

Valettiopsids also show affinities to the Miramarassidae. Both have uropods 1 and 2 without apical robust setae, deeply cleft telsons, elongate ischia on the second gnathopods with rectolinear carpi and propodi, a lacinia mobilis on both mandibles, inner plates of maxillae 1 with setae along the medial margins and rami of third uropods longer than the peduncles. But among other differences the miramarassids apparently have no callynophore nor posteroventral lobe on the pereopod 4 coxa and the structure of the antenna 1 peduncular articles are different.

Valettiopsids also appear to be related to eusirids (sensu stricto). They differ in the well developed accessory flagellum (minute or scale-like in eusirids), in the inner plate of maxilla 1 which has setae along the entire medial margin (apical in eusirids) and in the long ischium on gnathopod 2 (short in eusirids).

Distribution. Known from about $50^{\circ}$ north to $40^{\circ}$ south in the Atlantic and Pacific Oceans, $183-6000 \mathrm{~m}$ depth. Also known from an anchialine cave in the Galapagos Islands, 17-29 m depth (Stock \& Iliffe 1990).

\section{Key to Genera \\ (modified from Lincoln \& Thurston 1983)}

1. Gnathopod 1 coxa large, subequal to coxa of gnathopod 2.

Urosomite 1 without strong acute tooth Valettietta

- Gnathopod 1 coxa reduced, smaller than coxa of gnathopod 2.

Urosomite 1 with strong acute tooth

Valettiopsis

\section{Acknowledgements}

Our thanks to Helen Stoddart for many constructive comments on the manuscript and to Lauren Hughes for composing the figures.

\section{References}

Barnard, J.L. (1969) The families and genera of marine gammaridean Amphipoda. United States National Museum Bulletin, 271, i-vi, 1-535.

Barnard, J.L. \& Ingram, C.L. (1986) The supergiant amphipod Alicella gigantea Chevreux from the North Pacific gyre. Journal of Crustacean Biology, 6(4), 825-839.

Barnard, J.L. \& Ingram, C.L. (1990) Lysianassoid Amphipoda (Crustacea) from deep-sea thermal vents. Smithsonian Contributions to Zoology, 499, 1-80.

Barnard, J.L. \& Karaman, G.S. (1991) The families and genera of marine gammaridean Amphipoda (except marine gammaroids). Records of the Australian Museum, Supplement, 13(1/2): 1-866.

Bousfield, E.L. (1979) A revised classification and phylogeny of amphipod crustaceans. Transactions of the Royal Society of Canada, Series 4, 16, 343-390. 
Bousfield, E.L. (1987) Amphipod parasites of fishes of Canada. Canadian Bulletin of Fisheries and Aquatic Sciences, $217,1-37$.

Chevreux, E. (1899) Sur deux espèces géantes d'amphipodes provenant des campagnes du yacht Princesse Alice. Bulletin de la SociÈtÈ Zoologique de France, 24, 152-158.

Chevreux, E. (1903) Campagnes scientifiques de S.A. le Prince Albert Ier de Monaco. Note prÈliminaire sur les amphipodes de la famille des Lysianassidae recueillis par la Princesse Alice dans les eaux profondes de l'Atlantique et de la MÈditerranÈe. Bulletin de la SociÈṫ̀ Zoologique de France, 28, 81-97.

Chevreux, E. (1908) Diagnoses d'amphipodes nouveaux provenant des campagnes de la Princesse Alice dans l'Atlantique nord. Bulletin de l'Institut OcĖanographique, Monaco, 117, 1-13.

Dallwitz, M.J. (2005) Overview of the DELTA System. http://delta-intkey.com/www/overview.htm.

Dana, J.D. (1849) Synopsis of the genera of Gammaracea. American Journal of Science and Arts, Series 2, 8: 135-140.

De Broyer, C. \& Thurston, M.H. (1987) New Atlantic material and redescription of the type specimens of the giant abyssal amphipod Alicella gigantea Chevreux (Crustacea). Zoologica Scripta, 16(4), 335-350.

Hendrycks, E.A. (2007) A new species of Valettiopsis Holmes, 1908 (Crustacea: Gammaridea: Lysianassoidea) from abyssal waters off California. Zootaxa, 1501, 45-56.

Holmes, S.J. (1908) The Amphipoda collected by the U.S. Bureau of Fisheries steamer "Albatross" off the west coast of North America, in 1903 and 1904, with descriptions of a new family and several new genera and species. Proceedings of the United States National Museum, 35, 489-543.

Horton, T. (2004) Revision of the amphipod genus Valettiopsis Holmes, 1908 (Crustacea: Lysianassoidea), with the addition of three new species. Journal of Natural History, 38(14), 1735-1755.

Lilljeborg, W. (1865) On the Lysianassa magellanica H. Milne Edwards, and on the Crustacea of the suborder Amphipoda and subfamily Lysianassina found an [sic] the coast of Sweden and Norway, Royal Academic Press, Uppsala. 38 pp.

Lincoln, R.J. \& Hurley, D.E. (1981) The calceolus, a sensory structure of gammaridean amphipods (Amphipoda: Gammaridea). Bulletin of the British Museum (Natural History), Series Zoology, 40(4), 103-116.

Lincoln, R.J. \& Thurston, M.H. (1983) Valettietta, a new genus of deep-sea amphipod Gammaridea: Lysianassidae) with descriptions of two new species from the north Atlantic Ocean. Bulletin of the British Museum (Natural History), Series Zoology, 44(2), 85-101.

Lowry, J.K. (2006) New families and subfamilies of amphipod crustaceans. Zootaxa, 1254, 1-28.

Lowry, J.K. \& Stoddart, H.E. (1990) The Wandinidae, a new Indo-Pacific family of lysianassoid Amphipoda (Crustacea). Records of the Australian Museum, 42(2), 159-171.

Lowry, J.K. \& Stoddart, H.E. (1995) The Amphipoda (Crustacea) of Madang Lagoon: Lysianassidae, Opisidae, Uristidae, Wandinidae and Stegocephalidae. Records of the Australian Museum, Supplement, 22, 97-174.

Lowry, J.K. \& Stoddart, H.E. (1996) New lysianassoid amphipod species from Namibia and Madagascar (Lysianassidae Dana, 1849 and Podoprionidae fam. nov.). Bollettino del Museo Civico di Storia Naturale di Verona, 20, $225-247$.

Lowry, J.K. \& Stoddart, H.E. (1997) Amphipoda Crustacea IV. Families Aristiidae, Cyphocarididae, Endevouridae, Lysianassidae, Scopelocheiridae, Uristidae. Memoirs of the Hourglass Cruises, 10, 1-148.

Lowry, J.K. \& Stoddart, H.E. (2002) The Amaryllididae of Australia (Crustacea: Amphipoda: Lysianassoidea). Records of the Australian Museum, 54(2), 129-214.

Schellenberg, A. (1926) Amphipoda 3: Die Gammariden der Deutschen Tiefsee-Expedition. Wissenschaftliche Ergebnisse der Deutschen Tiefsee-Expedition auf dem Dampfer "Valdivia" 1898-1899, 23, 193-243, pl. 195.

Serejo, C.S. \& Wakabara, Y. (2003) The genus Valettiopsis (Crustacea, Gammaridea, Lysianassoidea) from the southwestern Atlantic, collected by the RV Marion Dufresne. Zoosystema, 25, 187-196.

Stebbing, T.R.R. (1888) Report on the Amphipoda collected by H.M.S. Challenger during the years 1873-1876. Report on the Scientific Results of the Voyage of H.M.S. Challenger during the years 1873-76, Zoology, 29, 1-1737, pls 1731-1210.

Stock, J.H. \& Iliffe, T.M. (1990) Amphipod crustaceans from anchihaline cave waters of the Galapagos Islands. Zoological Journal of the Linnean Society, 98, 141-160.

Stoddart, H.E. \& Lowry, J.K. (2004) The deep-sea lysianassoid genus Eurythenes (Crustacea, Amphipoda, Eurytheneidae n. fam.). Zoosystema, 26(3), 425-468.

Thurston, M.H. (1989) A new species of Valettia (Crustacea: Amphipoda) and the relationship of the Valettidae to the Lysianassoidea. Journal of Natural History, 23(5), 1093-1107. 